\title{
Attention Deficit Hyperactivity (ADHD) and Autism Spectrum Disorder (ASD): on the Role of Alcohol and Societal Factors
}

\author{
Sergei V. Jargin ${ }^{1, *}$ \\ ${ }^{1}$ Department of Public Health, Peoples' Friendship University of Russia, Moscow, Russia \\ * Corresponding author: Sergei V. Jargin, Department of Public Health, Peoples' Friendship University of Russia, Clementovski Per 6-82;115184, Moscow, Rus- \\ sia. Tel.: +7-4959516788, Fax: +7-4959516788, E-mail: sjargin@mail.ru
}

Keywords: Autistic Disorder; Hyperactivity; Alcoholism

\section{Dear Editor,}

ADHD predicts future substance abuse/dependence (1). In the West, the earlier shift from behavioral to neurological emphasis concerning ADHD was revised (2), while Russian literature places neurophysiologic mechanisms into the foreground. ASD cases are often marked by symptoms consistent with ADHD (3). This letter continues the paper (4), where a case of child abuse was discussed. The following risk factors of child abuse (5), were present in that case: young age of the abusing stepfather, who was 15 years older than his victim $(S)$, maltreatment history in the abuser's past. An ethnic factor played a role: the abuser was of Jewish descent, while S used to stress his Russian ethnicity. Having a Jewish stepfather, who even worked for some time at his school, $\mathrm{S}$ was often treated by the social environment as a member of the ethnic minority. It was expressed by bullying, sometimes visibly inspired by elders including some teachers and other children's relatives. The author does not intend to say that Jewish children were generally bullied at Soviet schools. Many of them were not, because they had been better prepared, did not deny their difference, and behaved adequately. On the contrary, S behaved ambitiously, involuntarily provoking his social environment. $S$ himself participated in bullying children from ethnic minorities, which cannot be morally justified, but is psychologically explicable in this case. His role should be classified as bully-victim, reportedly more at risk of substance use than pure bullies or victims (6). Apart from occasional participation in parties at home and drinking up to a bottle of beer with a schoolmate, $S$ had not used alcohol till the age of 13 years, when he consumed a $750 \mathrm{~mL}$ bottle of a Port imitation with an older boy. During the following year, his alcohol consumption increased up to $250 \mathrm{~mL}$ of vodka with beer or $750 \mathrm{~mL}$ of fortified wine at one session. An opportunity to stay away from the abusive atmosphere at home was provided by a company of schoolmates including older boys, who inspired alcohol purchase and consumption (7). However, S did not develop physical dependence and discontinued alcohol misuse later in life. Furthermore, at the age of about five years, $S$ presented with commu-

Article type: Letter; Received:13 Dec 2012, Revised: 17 Dec 2012, Accepted:17 Dec 2012.

Implication for health policy/practice/research/medical education:

Considerations about etiology of autism spectrum disorder (ASD) and its possible relationship with the attention deficit hyperactivity disorder (ADHD). Possible mechanisms leading to the alcohol misuse in both conditions. Conclusions of the letter might be useful for policy planning in health care and education.

Please cite this paper as:

Jargin SV. Attention Deficit Hyperactivity (ADHD) and Autism Spectrum Disorder (ASD): on the Role of Alcohol and Societal Factors. Int J High Risk Behav Addict. 2013; 1(4): 194-5. DOI: 10.5812/ijhrba.9640

Copyright (C) 2013, NewPub.; Published by NewPub.

This is an Open Access article distributed under the terms of the Creative Commons Attribution License (http://creativecommons.org/licenses/by/3.0), which permits unrestricted use, distribution, and reproduction in any medium, provided the original work is properly cited. 
nication deficits, failure to develop appropriate peer relationships, motor clumsiness, and other symptoms of ASD. Some AHDH symptoms were observed as well, inattention, impulsivity and hyperactivity, the latter being more prominent in a familiar environment. Appearance of the autistic symptoms coincided with the time when the socially unskilled child became a victim of bullying. On the author's opinion, physical abuse is an undervalued cause of ASD, some ASD children probably are battered ADHD children or initially healthy ones. A child in the atmosphere of bullying cannot permit himself some ADHD manifestations described by the collective terms impulsivity and hyperactivity. Moreover, child abuse is associated with inadequate parenting (8), therefore, heritability of ASD can be caused not only by genetic but also by social factors. Children of deviant parents may be more exposed to maltreatment, as a result acquiring deviant features themselves.

\section{Authors' Contribution}

The whole article has been written by the author.

\section{Financial Disclosure}

There are no relevant financial interests.

\section{References}

1. Bayrami M, Goradel JA, Hashemi T, Mahmood-Alilu M. Predicting a tendency to use drugs from child and adult attention deficit hyperactivity disorder symptoms in adults. Int J High Risk Behav Addict.2012;1(3):104-8.

2. Börger NA.Attention Deficit Hyperactivity Disorder and State Regulation.2000.

3. Murray MJ. Attention-deficit/Hyperactivity Disorder in the context of Autism spectrum disorders. Curr Psychiatry Rep.2010;12(5):382-8.

4. Jargin SV. Letter from Russia: child abuse and alcohol misuse in a victim. Alcohol Alcohol.2011;46(6):734-6.

5. Hindley N, Ramchandani PG, Jones DP. Risk factors for recurrence of maltreatment: a systematic review. Arch Dis Child.2006;91(9):744-52.

6. Radliff KM, Wheaton JE, Robinson K, Morris J. Illuminating the relationship between bullying and substance use among middle and high school youth. Addict Behav.2012;37(4):569-72.

7. Jargin SV. On the causes of alcoholism in the former Soviet Union. Alcohol Alcohol.2010;45(1):104-5.

8. Gonzalez A, MacMillan HL. Preventing child maltreatment: an evidence-based update. J Postgrad Med.2008;54(4):280-6. 